Boise State University

ScholarWorks

3-2021

\title{
Research Data Management Competencies Self-Assessment
}

\author{
Michelle Armstrong \\ Boise State University \\ Megan Davis \\ Boise State University \\ Ellie Dworak \\ Boise State University \\ Yitzhak Paul \\ Boise State University \\ Elisabeth Shook \\ Boise State University
}

\section{c) (i) (2)}

This work is licensed under a Creative Commons Attribution-Share Alike 3.0 License.

\section{Recommended Citation}

Armstrong, Michelle; Davis, Megan; Dworak, Ellie; Paul, Yitzhak; and Shook, Elisabeth. (2021). "Research Data Management Competencies Self-Assessment". Data Management Services. Paper 8.

https://doi.org/10.18122/dataservices.8.boisestate

Related Publications:

Armstrong, Michelle; Davis, Megan; Dworak, Ellie; Paul, Yitzhak; and Shook, Elisabeth. (2022). "Research Data Management Stone Soup: Gauging Team Competencies: Gauging Team Competencies". In K. Getz and M. Brodsky (Eds.), The Data Literacy Cookbook (pp. 211-213). ACRL. https://scholarworks.boisestate.edu/lib_facpubs/168/ 
Research Data Management Competencies Self-Assessment

Instructions: Make a copy of this document; for each row, place an X in the column corresponding to your skill level; add questions or comments to the Notes column on the right.

\section{Name:}

Date:

I. RDM competencies

Developing Competent Proficient

Expert

Notes:

1. Understands data \& data management practices

1.1. Ability to identify likely data outputs based on descriptions of intricate research projects

1.2. Understands \& can articulate the research lifecycle \& where data management fits in

1.3. Locates, understands, \& applies DMP guidance \& best practices

1.4. Understands \& applies best practices for file naming \& organization

1.5. Understands \& applies best practices for preservation \& distribution of research data

1.6. Locates, understands, \& applies metadata standards

1.7. Understands issues \& applies best practices in data sharing \& reuse

1.8. Familiar with tools used to work with data

1.9. Understands data cleaning processes as well as when they are necessary

1.10. Understands how to create schema specific metadata

1.11. Understands the steps in curating \& publishing data sets

1.12. Understands the steps involved in archiving data sets (with regard to format \& preservation issues)

2. Familiar with data citation systems

2.1. Understands how to cite data such that it is easy for others to locate

2.2. Locates \& applies data citation styles such as APA \& MLA

3. Writes data management plans to follow best practices \& NSF directorate guidelines as well as meet researchers \& project needs

3.1. Identifies \& uses guidance \& documentation appropriate to the funding agency \& project

3.2. Includes guiding/supporting information specific to project needs

3.3. Identifies data management problems \& recommends solutions 


\section{RDM competencies continued}

4. Knowledge of intellectual property rights \& licensing, especially regarding data as scholarship

4.1. Understands \& can articulate when copyright, patents, or trade secrets might apply to a research project

4.2. Understands \& can articulate issues in licensing as it applies to publication \& repositories

4.3. Identifies when to refer researchers to the Office of Technology Transfer

5. Familiar with research data repositories

5.1. Locates \& refers researchers to the best options for a given type of research data

6. Can create organizational structures for researchers \& research teams

6.1. Generates ideas for structures

6.2. Identifies tools for implementation

6.3. Creates procedures \& documentation

6.4. Recommends strategies for successful implementation

7. Knowledge of the research process across a variety of disciplines

7.1. Understands research designs used within a variety of disciplines

7.2. Understands statistical methods used within a variety of disciplines

\section{Interpersonal competencies}

1. Communicates clearly verbally \& in writing

1.1. Effectively explains \& kindles enthusiasm for research data management

1.2. Effectively explains various aspects of research data management (metadata, organizational structure, elements of a $D M P)$

1.3. Distills complex concepts for non-experts

2. Builds relationships \& networks

2.1. Collaborates effectively

2.2. Maintains communication with stakeholders

2.3. Fosters trust \& readiness to accept change 
2.4. Requests \& integrates constructive criticism from team

2.5. Requests feedback from the researcher on the product of the consultation

2.6. Indicates willingness to offer further help

2.7. Develops \& maintains trusted relationships with researchers \& support partners

2.8. Gauges \& responds to researcher's readiness \& commitment to adopt data management practices

3. Sets reasonable boundaries

3.1. Negotiates timeline with researchers

\section{Academic environment competencies}

1. Commitment to staying current in a quickly evolving research environment

2. Understands the environment of higher education \& federal/state grants

3. Familiarity with institutional stances on intellectual property technology transfer

\section{Library professional competencies}

Notes:

1. Manages projects to completion

1.1. Provides product of consultations in a timely manner

2. Demonstrates a spirit of lifelong learning

2.1. Quickly locates \& comprehends contextual information about disciplinary research

2.2. Is willing to help researchers with complex questions

2.3. Finds connections in themes of projects \& problems

3. Understands \& models ethical behavior, e.g. regarding research compliance, information security, \& intellectual property

3.1. Respects researcher privacy \& maintains confidentiality

4. Identifies gaps in one's own and others' comprehension

4.1. Clarifies confusing terminology \& jargon

4.2. Asks clarifying questions as appropriate

5. Conducts a thorough data management needs interview 


\section{Library professional competencies continued}

5.1. Prepares \& organizes questions in advance of the interview

5.2. Identifies researchers' goals \& objectives

5.3. Clarifies researchers' needs \& issues

5.4. Can diverge from prepared questions as needed during the interview

5.5. Employs a system of triage to identify and prioritize opportunities to serve researchers.

6. Identifies appropriate expertise \& resources

6.1. Cites sources consulted in preparing recommendations

7. Understands \& applies assessment \& evaluation strategies to data management services

8. Facilitates knowledge transfer across organization

\section{Technical competencies}

1. Literate with computer hardware and software used in a university research data setting

1.1. Able to utilize hardware such as workstations, printers, scanners, and $3 D$ printers \& can address gaps in knowledge to acquire necessary skills

1.2. Acquainted with available research lifecycle software tools including knowledge of popular analysis \& visualization software

1.3. Knowledge of popular data analysis \& visualization software

1.4. Ability to use basic command line operations for file \& data manipulation

1.5. Familiar with relevant coding languages such as $R \&$ Python

\begin{tabular}{|c|c|c|c|c|}
\hline VII. Entrepreneurial competencies & Developing Competent & Proficient & Expert & Notes: \\
\hline 1. Communicates about \& markets research support services & & & & \\
\hline 2. Is willing to embrace failure & & & & \\
\hline $\begin{array}{l}\text { 3. Prioritizes research support services to meet organizational } \\
\text { needs }\end{array}$ & & & & \\
\hline
\end{tabular}

${ }^{1}$ Reference and User Services Association, 2013 
Sources:

American Library Association."Knowledge and competencies statements." Accessed March 3, 2021.

http://www.ala.org/educationcareers/careers/corecomp/corecompspecial/knowledgecompetencies.

Association of College \& Research Libraries. "Roles and Strengths of Teaching Librarians." April 28, 2017. http://www.ala.org/acrl/standards/teachinglibrarians.

Association of Southeastern Research Libraries. "Shaping The Future: ASERL's Competencies For Research Librarians." November 10, 2000. http://www.aserl.org/programs/competencies/.

"NASIG Core Competencies for Scholarly Communication Librarians," NASIG Newsletter 32, no. 5 (August 2017). Available at: https://tigerprints.clemson.edu/nasig/vol32/iss5/1.

Reference and User Services Association. "Guidelines for Behavioral Performance of Reference and Information Service Providers." Latest revisions approved May 28, 2013. http://www.ala.org/rusa/resources/quidelines/quidelinesbehavioral.

Schmidt, Birgit and Kathleen Shearer. "Librarians' Competencies Profile for Research Data Management." Joint Task Force on Librarians' Competencies in Support of EResearch and Scholarly Communication, June 2016. https://www.coar-repositories.org/files/Competencies-for-RDM_June-2016.pdf.

Research Data Management Competencies Self-Assessment by Michelle Armstrong, Megan Davis, Ellie Dworak, Yitzhak Paul, and Elisabeth Shook is licensed under a Creative Commons Attribution-ShareAlike 4.0 International License. 